\title{
Correction to: Contribution of thrips to seed production in Habenaria radiata, an orchid morphologically adapted to hawkmoths
}

\author{
Koji Shigeta $^{1} \cdot$ Kenji Suetsugu $^{2}$ (D)
}

Published online: 6 June 2020

(C) The Botanical Society of Japan 2020

\section{Correction to: Journal of Plant Research https://doi.org/10.1007/s10265-020-01205-z}

In the original publication of the article, Fig. $2 \mathrm{c}$ was erroneously identical with Fig. 2a and correct version is provided below.

$\triangle$ Kenji Suetsugu

kenji.suetsugu@gmail.com

1 Food Technology Research Center, Hiroshima Prefectural Technology Research Institute, 12-70 Hijiyama-honmachi, Minami-ku, Hiroshima 732-0816, Japan

2 Department of Biology, Graduate School of Science, Kobe University, 1-1 Rokkodai, Nada-ku, Kobe 657-8501, Japan 

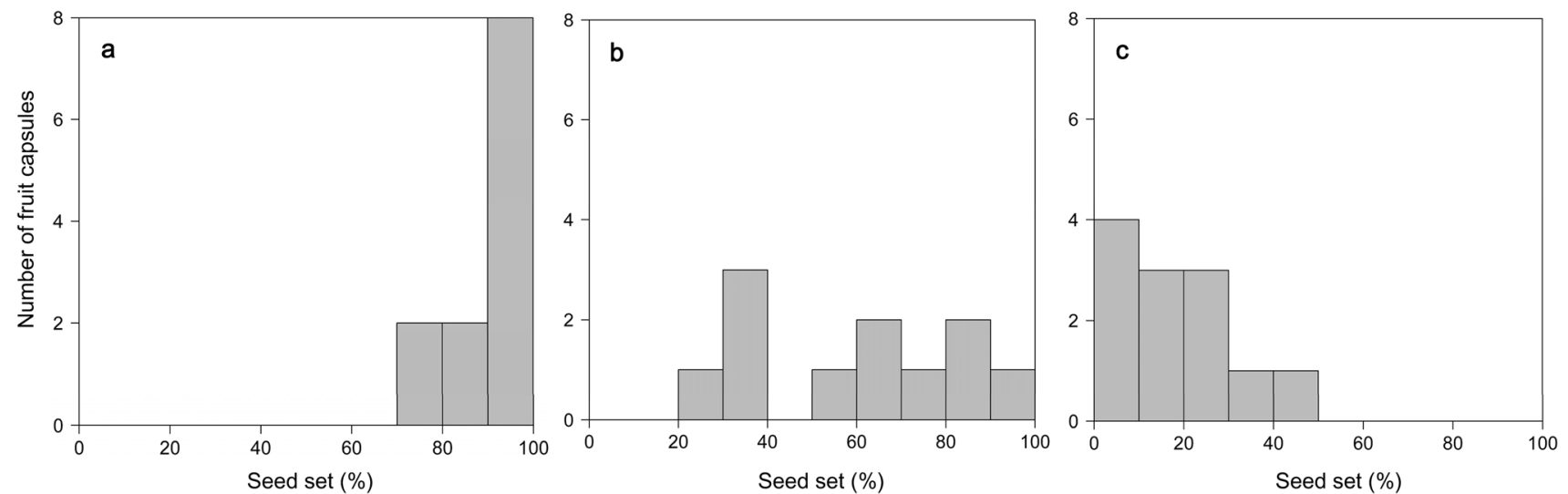

Fig. 2 Histograms of the seed set of Habenaria radiata from manually cross-pollinated flowers (a), open-pollinated flowers (b), and from flowers bagged with mesh bags (c)

Publisher's Note Springer Nature remains neutral with regard to jurisdictional claims in published maps and institutional affiliations. 